\title{
PERAN PENGADILAN HUBUNGAN INDUSTRIAL PADA PENGADILAN NEGERI PADANG KELAS IA DALAM MEMBERIKAN KEPASTIAN HUKUM TERHADAP PERKARA PEMUTUSAN HUBUNGAN KERJA
}

\author{
Rustan Sinaga ${ }^{1}$, Mashudi1 $^{2}$, Iyah Faniyah ${ }^{3}$ \\ Program Studi Pascasarjana Ilmu Hukum \\ Universitas Ekasakti Padang
}

\begin{abstract}
Termination of employment has a very complex impact and tends to cause disputes between employers and workers. in various laws and regulations, mechanisms and procedures for termination of employment have been regulated with the aim that both businessman and workers can maintain their normative rights. Since the enactment of Law No. 2 of 2004 concerning Industrial Relations Disput, the handling of employment disputes is the authority of the Industrial Relations Court at the local District Court. in addition to the judicial route (litigation) the settlement of disputes over termination of employment can also be settled outside the court (non litigation). In this study the author will focus on the settlement through justice (litigation). the issues discussed in this paper are the Roles of the Industrial Relations Court in Providing Legal Certainty to Termination of Employment (PHK) and the Implementation of Industrial Relations Court Decision by the Parties. in Writing this thesis the author uses the research of empirical law with normative juridical approach method supported by empirical juridical approach. Legal material collection techniques are carried out by means of library research and field research. The role of the Industrial Relations Court in the Padang Class IA Court, has resolved the case brought by the justice seekers to them, thereby granting the legal status in accordance with Law Number 2 of 2004 on Industrial Relations Dispute Settlement. The implementation of the Industrial Relations Court Decision by the Parties has not been carried out optimally in according to the PHI decision in the Padang Class IA District Court, because there are no strict sanctions against disobedience of the parties who did not carry out the decision, namely the employer as the convicted party to carry out the PHI decision in the Padang Class IA District Court. Therefore, against those who do not comply with the ruling IRC, should be subject to strict sanctions in the form of temporary revocation of business licenses, and government needs to make regulations to regulate the sanctions against parties who do not comply with the ruling of the IRC in Padang Class IA Court on particular and the Industrial Relations Court at the General Courts in general.
\end{abstract}

Kata Kunci : Industrial, Kepastian Hukum Pemutusan, Hubungan Kerja.

\section{PENDAHULUAN}

Agar dapat membeli, memperoleh atau membiayai segala benda atau sarana diperlukan penghasilan. Demikian juga untuk mempertahankan segala kekayaan dan sarana yang telah dimiliki atau secara rutin dapat digunakan untuk memenuhi segala keperluan hidupnya. Untuk mendapatkan penghasilan guna memenuhi berbagai keperluan hidupnya itulah setiap orang memerlukan orang lain dalam hubungan saling bantu-membantu atau saling tukar bantu dalam memberikan segala sesuatu yang telah dimiliki dan saling 
memberikan segala sesuatu yang diperlukan dari orang lain. ${ }^{1}$

Tenaga kerja memiliki peran dan kedudukan yang sangat penting sebagai pelaku (actor) dalam mencapai tujuan pembangunan. Sejalan dengan itu, pembangunan ketenagakerjaan diarahkan untuk meningkatkan kualitas dan kontribusinya dalam pembangunan serta melindungi hak dan kepentingannya sesuai dengan harkat dan martabat kemanusiaan. ${ }^{2}$

Pasal 3 Undang-undang Nomor 13 Tahun 2003 tentang Ketenagakerjaan (UU Ketenagakerjaan) yang mengatakan Pembangunan ketenagakerjaan diselenggarkan atas asas keterpaduan dengan melalui koordinasi dengan melalui koordinasi fungsional lintas sektoral pusat dan daerah. Oleh karena itu sebagaimana ditetapkan dalam Pasal 4 UU Ketenagakerjaan bahwa pembangunan ketenagakerjaan bertujuan untuk:

1. Memberdayakan dan mendayagunakan tenaga kerja secara optimal dan dan manusiawi;

2. Mewujudkan pemerataan kesempatan kerja dan penyediaan tenaga kerja yang sesuai dengan kebutuhan pembangunan nasional dan daerah;

\footnotetext{
1 A. Ridwan Halim dan Sri Subiandini Gultom, Sari Hukum Perburuhan Aktual, PT Pradnya Paramita, Jakarta, 1987, hlm. 1.

${ }^{2}$ B. Siswanto Sastrohadiwiryo, Manajemen tenaga kerja Indonesia, Pendekatan Administrasi dan Operasional, PT. Bumi Akasara, Jakarta 2005, hlm. 1.
}

3. Memberikan perlindungan kepada tenaga kerja dalam mewujudkan kesejahteraan; dan

4. Meningkatkan kesejahteraan tenaga kerja dan keluarganya.

Hubungan kerja terjadi apabila seseorang (karyawan, pekerja atau pegawai) menyediakan keahlian dan tenaganya untuk orang lain (majikan atau pimpinan) sebagai imbalan pembayaran sejumlah uang. Pekerjaan itu dapat dilakukan selama jangka waktu tertentu atau tidak tertentu, lama atau singkat, atau sampai suatu pekerjaan tertentu itu diselesaikan, tetapi pada umumnya pihakpihak lebih terikat secara teratur. Sebuah perusahaan dapat mempekerjakan beberapa direkturnya dengan membuat suatu perjanjian kerja dan menjadi anggota serikat buruh. Jika terjadi suatu perselisihan yang mengakibatkan terjadinya pemutusan hubungan kerja (PHK), maka serikat buruhlah yang akan memberikan perlindungan hukum terhadap para pekerjanya. $^{3}$

Perjanjian kerja diatur dalam Bab IX UU Ketenagakerjaan. Dalam Pasal 1 Angka 14 Undang-undang Ketenagakerjaan disebut bahwa Perjanjian kerja adalah perjanjian antara perkerja/buruh dengan pengusaha atau pemberi kerja yang memuat syarat-syarat

3 S.B. Marsh dan J. Soulsby dialih bahasa oleh Abdulkadir Muhammad, Hukum Perjanjian, PT. Alumni, Bandung, 2017, hlm. 315. 
kerja, hak dan kewajiban para pihak. Berdasarkan ketentuan tersebut, maka di dalam perjanjian kerja harus dipenuhi 3 (tiga) unsur, sebagai berikut: ${ }^{4}$

1. Ada orang di bawah pimpian orang lain;

2. Penunaian kerja maksudnya melakukan pekerjaan;

3. Adanya upah.

Dipenuhinya 3 (tiga) unsur tersebut, yaitu adanya perintah, pekerjaan dan upah disebut perjanjian kerja. Adapun pihak yang memerintah disebut pengusaha/pemberi kerja, sedangkan pihak yang diperintah disebut pekerja. $^{5}$

\section{Pasal 151 UU Ketenagakerjaan} berbunyi Ayat (1) Pengusaha, pekerja/buruh, serikat pekerja/serikat buruh, dan pemerintah, dengan segala upaya harus mengusahakan agar jangan terjadi pemutusan hubungan kerja. Sementara dalam ayat (2) Dalam hal segala upaya telah dilakukan, tetapi pemutusan hubungan kerja tidak dapat dihindari, maka maksud pemutusan hubungan kerja wajib dirundingkan oleh pengusaha dan serikat pekerja/serikat buruh atau dengan pekerja/buruh apabila pekerja/buruh yang bersangkutan tidak menjadi anggota serikat pekerja/serikat buruh.

Namun PHK terhadap pekerja/buruh banyak yang diajukan ke Pengadilan

\footnotetext{
${ }^{4}$ A. Ridwan Halim dan Sri Subiandini Gultom, Op.Cit. hlm. 8.

${ }^{5}$ F.X Djumialdji, Perjanjian Kerja, Sinar grafika Offset, Jakarta, 2005, hlm. 9.
}

Hubungan Industrial. Jumlah perkara sePropinsi Sumatera Barat berdasarkan data yang tercatat di Pengadilan Hubungan Industrial pada Pengadilan Negeri Padang Kelas IA adalah sebanyak 108 perkara, dengan rincian sebai berikut: tahun 2016 jumlah perkara sebanyak 55 perkara dan tahun 2017 sebanyak 53 perkara. $^{6}$

Seiring dengan kebebasan pekerja/buruh untuk mengorganisasikan dirinya, maka tugas yang diemban pekerja/buruh semakin berat, yakni tidak saja memperjuangkan hak-hak normatif pekerja/buruh, tetapi juga memberikan perlindungan, pembelaan dan mengupayakan peningkatan kesejahteraan pekerja/buruh terutama jika pekerja/buruh terlibat perselisihan yang mengakibatkan terjadinya PHK. $^{7}$

Apabila para pihak yang berselisih melakukan upaya penyelesaian melalui pengadilan, maka di dalam Pasal 55 UU PPHI yang berwenang memeriksa, mengadili dan memutuskan perselisihan hubungan industrial adalah PHI yang merupakan pengadilan khusus yang berada pada lingkungan peradilan umum. PHI bertugas dan berwenang memeriksa dan memutus ditegaskan dalam Pasal 56 UU PPHI, yang meliputi:

6 http://pn-padang.go.id:8090/SIPP320/main, diunduh tanggal 18 Januari 2018.

7 Lalu Husni, Pengantar Hukum Ketenagakerjaan Indonesia, PT. RajaGrafindo Persada, Jakarta 2001, hlm.29. 
1. Di tingkat pertama mengenai perselisihan hak;

2. Di tingkat pertama dan terakhir mengenai perselisihan kepentingan;

3. Di tingkat pertama mengenai perselisihan pemutusan hubungan kerja;

Di tingkat pertama dan terakhir mengenai perselisihan antar serikat pekerja/serikat buruh dalam satu perusahaan.

Berdasarkan latar belakang pemikiran di atas, maka penelitiaN ini untuk mengetahui dan menganalisis Peran Pengadilan Hubungan Industrial Dalam Memberikan Kepastian Hukum Terhadap Perkara Pemutusan Hubungan Kerja (PHK).

\section{METODE PENELITIAN}

Untuk menjawab permasalahan seperti yang telah diuraikan diatas, maka dalam melaksanakan penelitian yang berfungsi sebagai acuan, sehingga hasil dari penelitian dapat menemui sasaran dan dapat dipertanggung jawabkan.

Penulis dalam karya tulis ini menggunakan metode pendekatan yuridis normatif yang didukung oleh pendekatan yuridis empiris. Menurut Jhony Ibrahim "Penelitian hukum yuridis normatif adalah tipe penelitian yang difokuskan untuk mengkaji penerapan kaidah-kaidah atau norma-norma dalam hukum positif".

8 Jhonny Ibrahim, Teori dan Metodologi Penelitian Hukum Normatif, PT Bayu Media Publishing, Malang, 2010, hlm. 295.
Sedangkan penelitian yurudis empiris menurut Ronny Hanitijo Soemitro adalah "mengidentifikasikan dan mengkonsepsikan hukum sebagai institusi sosial yang riil dan fungsional. ${ }^{9}$

Pendekatan yuridis normatif dalam penelitian ini digunakan untuk menguraikan bahan-bahan kepustakaan berupa peraturan perundang-undangan, buku-buku dan karya ilmiah yang terkait dengan masalah yang diteliti. Sementara, dalam penelitian hukum empiris yang menjadi fokus kajiannya pada bekerjanya hukum dalam masyarakat. Pendeka-pendekatan yang sering digunakan dalam penelitian hukum empiris, meliputi: a. pendekatan sosiologi hukum, b. pendekatan antropologi hukum dan c. pendekatan psikologi hukum. $^{10}$

Menurut Peter Mahmud Marzuki yang mengutip pendapat Philipus M. Hadjon memaparkan metode deduksi sebagaimana silogisme yang diajarkan oleh Aristoteles. Penggunaan metode deduksi berpangkal dari pengajuan premis mayor (pernyataan yang bersifat umum). Kemudian diajukan premis minor (bersifat khusus), dari kedua premis itu kemudian ditarik suatu kesimpulan atau conclusion. Akan tetapi di dalam argumentasi hukum, silogisme hukum tidak

\footnotetext{
${ }^{9}$ Ronny Hanitijo Soemitro, Metodologi Penelitian Hukum dan Jurimetri, Ghalia Indonesia, Jakarta,1990, hlm.12.

${ }^{10}$ Ibid. hlm. 23.
} 
sesederhana silogisme tradisional. ${ }^{11}$

Dari 19 (sembilan belas)

Penelitian ini menggunakan teknik analisis data dengan logika deduktif, logika deduktif atau pengolahan bahan hukum dengan cara deduktif yaitu menjelaskan suatu hal yang bersifat umum kemudian menariknya menjadi kesimpulan yang lebih khusus.

\section{HASIL PENELITIAN}

Hasil penelitian tentang Kepastian Hukum dalam Pemutusan Hubungan Kerja Melalui Pengadilan Hubungan Industrial Pada Pengadilan Negeri Padang Kelas Ia.

Perkara yang telah terdaftar di pengadilan hubungan industrial pada pengadialan negeri Padang kelas IA sejak tahun 2016 sampai dengan tahun 2017 adalah sebanyak 108 (seratus delapan) perkara.

Tabel 1 Jumlah perkara PHI pada Pengadilan Negeri Padang Kelas IA Tahun 2016 dan Tahun

\begin{tabular}{|l|c|c|c|}
\multicolumn{5}{|c}{2017} \\
\hline No. & Tahun & Jumlah & Keterangan \\
\hline 1. & 2016 & 55 & \\
\hline 2. & 2017 & 53 & \\
\hline & Jumlah & 108 & \\
\hline
\end{tabular}

Dari data tersebut meliputi semua jenis perselisihan hubungan industrial yang ada di wilayah hukum PHI pada Pengadilan Negeri Padang Kelas IA, yang terdiri dari 19 (Sembilan belas) kabupaten/kota terdapat penurunan jumlah perkara sebanyak 2 perkara atau sebesar $0.96 \%$.

${ }^{11}$ Peter Mahmud Marzuki, Penelitian Hukum, Op. Cit. hlm. 47. 
yang diajukan ke pengadilan hubungan industrial pada pengadilan negeri Padang kelas IA baru perselisihan pemutusan hubungan kerja. Sementara jenis perselisihan hak, perselisihan kepentingan dan perselisihan antar serikat pekerja/serikat buruh hanya dalam satu perusahaan belum pernah diajukan sama sekali.

Data ini menunjukkan bahwa pemutusan hubungan kerja (PHK) terhadap pekerja/buruh masih dilakukan sewenangwenang oleh pengusaha tanpa melalui penetapan dari lembaga penyelesaian perselisihan hubungan industrial. Karena sesuai ketentuan ketenagakerjaan yang berlaku bahwa pemutusn hubungan kerja dapat dilakukan setelah memperoleh penetapan dari lembaga penyelesaian perselisihan hubungan industrial. Terdapat penurunan perkara dari tahun 2016 ke tahun 2017 sebanyak 2 (dua) perkara atau sebesar $3.6 \%$.

Semua perkara yang didaftarkan di PHI pada Pengadilan Negeri Padang Kelas IA oleh para pihak berharap perkaranya dapat terselesaikan sesuai harapannya. Alat atau sarana penyelesaian perkara adalah melalui putusan hakim. Putusan hakim merupakan sebuah "mahkota", "puncak" dan "akta penutup" dari proses perkara perdata/PHI. ${ }^{12}$ Pada dasarnya putusan PHI tersebut adalah: perdamaian, verstek, gugur, tolak, tidak dapat diterima/ Niet Onvankelijke Verklaraad (NO), kabul sebagian, kabul seluruhnya.

Putusan PHI pada Pengadilan Negeri Padang Kelas IA terdapat beberapa kategori yaitu: putusan perdamaian, dilaksanakan dengan suka rela, kasasi dan peninjauan kembali.

Tabel 3

Status putusan PHI pada Pengadilan Negeri Padang Kelas IA setelah putusan akhir Tahun 2016 dan Tahunb 2017

\begin{tabular}{|l|l|r|r|r|r|}
\hline No. & Status Putusan akhir & \multicolumn{2}{|c|}{ Tahun } & Jumlah & Keterangan \\
\cline { 3 - 5 } & & 2016 & \multicolumn{1}{|c|}{2017} & & \\
\hline 1. & Perdamaian & 11 & 24 & 35 & \\
\hline 2. & $\begin{array}{l}\text { Dilaksanakan dengan } \\
\text { suka rela }\end{array}$ & 16 & 4 & 20 & \\
\hline 3. & Kasasi & 15 & 17 & 32 & \\
\hline 4. & Peninjauan Kembali & 4 & 1 & 5 & \\
\hline & Jumlah & 46 & 46 & 92 & \\
\hline
\end{tabular}

Pada dasarnya untuk pelaksanan putusan PHI tersebut dominan dilaksanakan di luar pengadilan dan tidak ada laporan atau pemberitahuan ke Pengadilan Hubungan Industrial pada Pengadilan Negeri Padang kelas IA. Jika dibuat dalam persentasenya adalah sebesar $21.1 \%$ yang telah dilaksnakan.

\section{PEMBAHASAN}

Peran Pengadilan Hubungan Industrial

Dalam Memberikan Kepastian Hukum

Terhadap Perkara Pemutusan Hubungan Kerja

Dalam proses persidangan perkara pemutusan hubungan kerja (PHK) yang diajukan oleh para pencari keadilan ke Pengadilan Hubungan Industrial pada

\footnotetext{
${ }^{12}$ Lilik Mulyadi dan Agus Subroto, Op. Cit, hlm. 233.
} 
Pengadilan Negeri Padang Kelas IA agar para pencari keadilan memperoleh keadilan, kemanfatan dan kepastian hukum terhadap perkara yang diajukan.

\section{Putusan Pengadilan Hubungan} Industrial menghasilkan berbagai macam putusan antara lain adalah putusan perdamaian, ditolak, tidak dapat diterima/NO, kabul, dan bahkan ada yang dicabut perkaranya. Putusan Pengadilan Hubungan Industrial yang mengabulkan gugatan/tuntutan penggugat baik mengabulkan sebahagian maupun seluruhnya masih terdapat upaya hukum yaitu kasasi dan peninjauan kembali. Para pihak dapat mempegunakannya sesuai dengan aturan perundang-undangan yang berlaku. Jika terhadap putusan PHI tidak dilakukan upaya hukum dan telah lewat tenggang waktu mengajukan upaya hukum, maka putusan tersebut menjadi putusan yang berkekuatan hukum tetap (BHT)/inkracht van gewijsde.

Putusan PHI yang sudah berkekuatan hukum tetap (BHT) bersifat mengikat dan memaksa. Mengikat diartikan bahwa putusan harus dipatuhi dan dilaksanakan. Sedangkan bersifat memaksa dimaknai bahwa putusan itu bisa dilaksanakan secara paksa kalau pihak yang dihukum tidak melaksankan secara suka rela. $^{13}$

13 Juanda Pangaribuan, Seluk beluk Hukum Acara....., Op. Cit. hlm. 65.
Putusan PHI dapat dilaksanakan dengan salah satu cara berikut ini: (1) dilaksanakan secara sukarela, sesuai amar putusan; (2) dilaksanaka dengan negosiasi, pembayaran tidak sama dengan amar putusan; (3) memaksa tergugat melaksanakan putusan melalui prosedur eksekusi pengadilan. Eksekusi dikenal sebagai upaya paksa. Pengadilan dapat memaksa tergugat melaksanakan putusan condemnatoir Untuk melaksanakan paksaan itu, pengadilan melakukan penyitaan, dilanjutkan dengan pelelangan barang tergugat. ${ }^{14}$

Pengadilan Hubungan Industrial telah melaksanakan sesuai dengan kewenanganya yaitu memeriksa, mengadili, dan memutus perselisihan hubungan industrial yang diajukan kepadanya. Berdasarkan pasal 56 UU PPHI, menyebutkan PHI bertugas dan berwenang memeriksa dan memutus:

1. Di tingkat pertamamengenai perselisihan hak;

2. Di tingkat pertama dan terakhir mengenai perselisihan kepentingan;

3. Di tingkat pertama mengenai perselisihan pemutusan hubungan kerja;

4. Di tingkat pertama dan terakhir mengenai perselisihan antar serikat pekerja/serikat buruh dalam satu perusahaan.

Putusan PHI yang mencerminkan kepastian hukum, hakim dalam menyelesaikan perkara atau perselisihan

${ }^{14}$ Ibid, hlm. 66. 
hubungan industrial mempunyai tugas untuk menemukan hukum yang tepat. Hakim dalam menemukan hukum, ${ }^{15}$ tidak cukup hanya mencari dalam undang-undang saja, sebab kemungkinan undang-undang tidak mengatur secara jelas dan lengkap, sehingga hakim harus menggali nilai-nilai hukum yang hidup dalam masyarakat.

Nilai-nilai hukum yang hidup dalam masyarakat tidak lain hukum adat dan hukum tidak tertulis. Hakim bertugas sebagai penggalinya dan merumuskannya dalam suatu putusan. Kepastia hukum yang dituangkan dalam putusan hakim merupakan hasil yang didasarkan pada fakta-fakta persidangan yang relevan secara yuridis serta dipertimbangkan dengan hati nurani. Peristiwa relevan tersebut nantinya dapat mempengaruhi penyelesaian perkara.

Berdasarkan data yang penulis peroleh dari PHI pada Pengadilan Negeri Padang Kelas IA selama mengadakan penelitian, penulis memperoleh data bahwa perkara pada tahun 2016 sebanyak 55 (lima puluh lima) perkara telah diputus dan di tahun 2017 sebanyak 53 (lima puluh tiga) perkara telah diputus sebanyak 51 (lima puluh satu) perkara. Sementara 2 (dua) perkara lagi masih dalam proses persidangan. Putusan PHI pada Pengadilan Negeri Padang Kelas IA tersebut dengan berbagai putusan seperti: perdamaian,

15 Bambang Sutiyoso, Implementasi gugatan Legal Standing Dan Class Action dalam Praktik Peradilan Di ditolak, tidak dapat diterima/ Niet Onvankelijke Verklaraad(NO), kabul sebagian dan kabul seluruhnya. Putusan perdamaian pada tahun 2016 dan tahun 2017 sebanyak 35 (tiga puluh lima) perkara atau sebesar 49.3\%. Dalam hal tercapainya perdamaian tersebut Majelis Hakim berperan untuk menyelesaikan perkara para pihak dengan musywarah untuk mufakat, dimana para pihak tidak ada yang kalah dan tidak ada yang menang, saling menguntungkan/win win solution.

Dari 16 (enam belas) jumlah putusan PHI yang elah berkekuatan hukum tetap (BHT) yang telah dilaksanakan sebanyak 3 (tiga) perkara, sementara sebanyak 13 (tiga belas) perkara tidak ada keterangan apakah putusan sudah dilaksanakan atau belum. Namun dari 13 (tiga belas) perkara tersebut, penulis memperoleh informasi dari responden bahwa putusan perkaranya masih belum dilaksanakan oleh pihak tergugat.

Berikut contoh/sampling putusan yang dilaksakan dan tidak/belum dilaksanakan.

1. Putusan yang dilaksanakan, putusan Nomor 39/Pdt.Sus PHI/2016/PN Pdg

2. Putusan yang tidak/belum dilaksanakan, contoh putusan Nomor 26/Pdt.SusPHI/2016/PN Pdg

Indonesia, Jurnal Hukum Ius Quia Iustum Vol. 26 No. 11, Mei 2004, Yogyakarta: FH UII, hlm. 77. 
Pelaksanaan Putusan Pengadilan

Hubungan Industrial Pada Pengadilan

\section{Negeri Padang Kelas IA Oleh Para Pihak}

Putusan yang dapat dieksekusi/ dilaksanakan harus merupakan Putusan yang sudah mempunyai kekuatan hukum tetap; yang terhadap Putusan tersebut tidak dapat lagi dilakukan upaya hukum lagi misalnya Kasasi. Putusan yang berkekuatan hukum tetap tersebut harus mengandung suatu penghukuman; (misalnya : penghukuman untuk melaksanakan suatu Putusan, menyerahkan suatu barang, mengosongkan sebidang tanah, menghentikan suatu perbuatan/keadaan, membayar sejumlah uang atau melakukan suatu perbuatan tertentu); serta putusan tersebut tidak dilaksanakan secara sukarela oleh pihak yang diperintahkan untuk memenuhi putusan tersebut.

Pihak yang menang berharap agar putusan PHI dapat dilaksanakan (eksekusi), sebab bila tidak dilaksanakan putusan pengadilan tersebut tidak bermakna. Dalam hal putusan pengadilan yang telah bekekuatan hukum tetap (inkrcht van gewijsde) tersebut dilaksankan dengan suka rela oleh pihak yang dikalahkan, sudah barang tentu hal tersebut tidak menimbulkan persoalan. Seiring degan hal ini, berarti bahwa perkara tersebut telah selesai. ${ }^{16}$
Hal ini berarti bahwa persolan eksekusi atas putusan PHI mengacu pada ketentuan hukum acara perdata. Terhadap pelaksanaan putusan PHI yang telah mempunyai kekuatan hukum tetap (BHT) terdapat kendala-kendala.

Kendala lain dalam pelaksanaan putusan PHI yaitu tidak adanya sanksi yang tegas yang diatur dalam peraturan perundangundangan bagi pihak yang tidak melaksanakan putusan $\mathrm{PHI}$ tersebut secara suka rela.

Terhadap putusan PHI yang telah memperoleh kekuatan hukum tetap, pihak yang kalah tetap tidak bersedia untuk mememenuhi putusan pengadilan tersebut. Kejadian seperti itu dapat saja terjadi di dalam praktik, karena pihak yang kalah walaupun sudah diputus oleh hakim, tetap saja tidak mau berbesar hati menerima kekalahan untuk melaksanakan isi putusan dengan suka rela. Seyogyanya pihak yang kalah baik itu pengusaha maupun pekerja, laksanakanlah isi putusan secara suka rela karena itu sudah menjadi kehendak para pihak itu sendiri membawa perselisihan untuk mendapat keadilan di hadapan hakim.

Untuk pelaksaan eksekusi terhadap putusan pengadilan hubungan industrial perlu diperhatikan asas-asas eksekusi terebut yaitu sebagai berikut:
a. Teguran atau Aanmaning
b. Pelaksanaan Sita Eksekusi

\footnotetext{
${ }^{16}$ Lilik Mulyadi dan Agus Subroto, Op. Cit. hlm. 283.
} 
c. Pelaksanaan Lelang Eksekusi

\section{PENUTUP}

Peran Pengadilan Hubungan Industrial pada Pengadilan Negeri Padang Kelas IA, telah menyelesaikan perkara yang diajukan oleh para pencari keadilan kepadanya, sehingga memberikan kepastia hukum sesuai dengan Undang-undang Nomor 2 Tahun 2004 tentang Penyelesaian Perselisihan Hubungan Industrial;

$$
\text { Pelaksanaan Putusan Pengadilan }
$$

Hubungan Industrial Oleh Para Pihak belum terlaksana maksimal sesuai amar putusan PHI pada Pengadilan Negeri Padang Kelas IA, karena masih ada putusan yang sudah berkekuatan hukum tetap/ inkracht van gewijde belum dilaksanakan oleh pihak perusahaan/pengusaha. Hal ini terjadi karena tidak adanya sanksi yang tegas terhadap ketidak patuhan para pihak yang tidak/belum melaksanakan amar putusan, yaitu pihak pengusaha sebagai pihak yang dihukum untuk melaksanakan amar putusan PHI pada Pengadilan Negeri Padang Kelas IA.

\section{DAFTAR PUSTAKA}

\section{Buku}

A. Ridwan Halim dan Sri Subiandini Gultom, Sari Hukum Perburuhan Aktual, PT Pradnya Paramita, Jakarta, 1987.

B. Siswanto Sastrohadiwiryo, 2005. Manajemen tenaga kerja Indonesia, Pendekatan Administrasi dan
Operasional, PT. Bumi Akasara, Jakarta.

F.X Djumialdji, 2005. Perjanjian Kerja, Sinar grafika Offset, Jakarta.

Jhonny Ibrahim, 2010. Teori dan Metodologi Penelitian Hukum Normatif, PT Bayu Media Publishing, Malang.

Juanda Pangaribuan, 2012. Aneka Putusan Mahkamah Konstitusi Bidang Hukum Ketenagakerjaan Dilengkapi Ulasan Hukum, Muara Ilmu Sejahtera Indonesia, Jakarta.

Lalu Husni, 2001. Pengantar Hukum Ketenagakerjaan Indonesia, PT. RajaGrafindo Persada, Jakarta.

Peter Mahmud Marzuki, 2007. Penelitian Hukum, Kencana Prenada Media Group, Jakarta.

Ronny Hanitijo Soemitro, 1990. Metodologi Penelitian Hukum dan Jurimetri, Ghalia Indonesia, Jakarta.

Ridwan Halim dan Sri Subiandini Gultom, 1987. Sari Hukum Perburuhan Aktual, PT Pradnya Paramita, Jakarta.

S.B. Marsh dan J. Soulsby dialih bahasa oleh Abdulkadir Muhammad, 2017. Hukum Perjanjian, PT. Alumni, Bandung.

\section{Undang - Undang}

Undang-Undang Dasar Negara Republik Indonesia Tahun 1945.

Kitab Undang-Undang Hukum Perdata (Burgerlijk Wetboek), Staatsblad Tahun 1847 Nomor 23.

Undang-undang Nomor 13 Tahun 2003 Tentang Ketenagakerjaan, Lembaran Negara Republik Indonesia Tahun 2003 Nomor 39, Tambahan Lembaran Negara Republik Indonesia Nomor 4279.

Undang-undang Nomor 2 tahun 2004 Tentang Penyelesaian Perselisihan Hubungan Industrial, Lembaran Negara Republik 
Indonesia Tahun 2004 Nomor 6, Tambahan Lembaran Negara Republik Indonesia Nomor 4356.

Undang-undang Nomor 5 Tahun 2004 tentang Perubahan Atas Undang-undang Nomor 14 Tahun 1985 tentang Mahkamah Agung dengan perubahan kedua dengan Undang-undang Nomor 3 Tahun 2009 tentang Perubahan Kedua Undang-undang Nomor 14 Tahun 1985 tentang Mahkamah Agung.

\section{Journal}

Bambang Sutiyoso, 2004. Implementasi gugatan Legal Standing Dan Class Action dalam Praktik Peradilan Di Indonesia, Jurnal Hukum Ius Quia Iustum Vol. 26 No. 11, Yogyakarta: FH UII.

\section{Website}

Http://Pnpadang.Go.Id:8090/Sipp320/Ma in, diunduh tanggal 18 Januari 2018 10:18 WIB.

Http://Pnpadang.Go.Id:8090/Sipp320/Det il_Kasasi, diunduh tanggal 25 Juli 2018 pukul 09:22 WIB.

Https://Kbbi.Web.Id/Peran, diunduh tanggal 28 November 2017 pukul 14:38 WIB. 